\title{
Dermatology
}

Dermatology 2009;218:73-74

DOI: $\underline{10.1159 / 000163085}$

\section{Efalizumab Rebound Response to a Sequential Therapy of Infliximab Followed by Efalizumab}

\author{
Alexandra Maria Giovanna Brunasso ${ }^{\mathrm{a}, \mathrm{b}}$, Chiara Delfino ${ }^{\mathrm{b}}$, \\ Cesare Massone ${ }^{c}$ \\ a Department of Dermatology, Galliera Hospital, Genoa, \\ and ${ }^{\mathrm{b}}$ Department of Dermatological Sciences, University \\ of Florence Medical School, Florence, Italy; ' ${ }^{\text {Department }}$ of \\ Dermatology, Research Unit of Dermatopathology, Medical \\ University of Graz, Graz, Austria
}

Key Words

Generalized pustular psoriasis - Infliximab - Efalizumab •

Relapse $\cdot$ Rebound response

In the January 2008 issue of Dermatology, Barde et al. [1] showed the feasibility of sequential therapy with infliximab and efalizumab in 5 patients. After 1 year, the results were not encouraging, and they concluded that further research was still needed. Herein, we report the case of a 49 -year-old woman, with a 20 -year history of severe chronic plaque psoriasis that was treated for several years with rotational topical therapy and phototherapy. In 2002, the patient was admitted because of a generalized eruption of sterile pustules associated with fever and malaise. Trigger factors were not found. The patient started therapy with acitretin (35 $\mathrm{mg}$ /day) with no improvement, and, after 4 weeks, ciclosporin was introduced at $4 \mathrm{mg} / \mathrm{kg} /$ day with complete clinical remission within 12 weeks. In May 2004, the classic plaque psoriasis reemerged, and the patient was admitted with a PASI of 32.3. Ciclosporin was reinitiated at $4 \mathrm{mg} / \mathrm{kg} /$ day with a partial response under PASI-50 after 8 weeks. At week 10, the dose was increased to $6 \mathrm{mg} / \mathrm{kg} /$ day with no improvement. After 4 weeks, we decided to introduce efalizumab at a conditioning dose of $0.7 \mathrm{mg} / \mathrm{kg} /$ week s.c. and subsequently at $1 \mathrm{mg} / \mathrm{kg} /$ week, with complete remission after 12 weeks. At week 20 of the efalizumab course, the patient spontaneously decided to withdraw therapy, and, 5 weeks later, a generalized pustular eruption accompanied by fever and dactylitis (severe onychodystrophy and paronychia on the 5th left finger, clinically resembling suppurative acrodermatitis of Hallopeau) was observed (fig. 1). No trigger factors were found. Infliximab therapy at $5 \mathrm{mg} / \mathrm{kg} /$ day i.v. was initiated in a regimen of 0,2 and 6 weeks, with consecutive infusions every 8 weeks because of the

This work was conducted at the Department of Dermatological Sciences, University of Florence Medical School, Florence, Italy. weak response after 10 days of ciclosporin and the immediate need to control the systemic disease. After 4 weeks, the patient was free of pustules but a slight erythema was still present. At week 14 , the patient was free of lesions, and, after the 5 th infusion, she requested the suspension of infliximab. Efalizumab was reintroduced with the maintenance of the excellent results (PASI-100) until the last follow-up visit 100 weeks after the first infliximab infusion and 58 weeks from the second cycle of efalizumab (fig. 2). The generalized pustular eruption seen 5 weeks after the efalizumab withdrawal might be classified either as generalized pustular psoriasis (GPP), i.e. a rebound phenomenon after efalizumab suspension, or as a GPP relapse (second episode). We favour the rebound hypothesis because of the time of onset ( 5 weeks). In fact, rebound is defined as the development of new widespread pustular, erythrodermic or more inflammatory psoriasis lesions occurring within 8 weeks from treatment discontinuation in responding patients [2]. Approximately $13 \%$ of treated patients develop a rebound phenomenon [2], although GPP after efalizumab withdrawal has rarely been reported. Gaylor and Duvic [3] reported a case of GPP occurring 2 weeks after efalizumab withdrawal, which may have been triggered by a concomitant herpes zoster infection.

Infliximab has been successfully used in patients with GPP, reporting a rapid and positive response without any significant side effects $[4,5]$, but, in the literature, infliximab and methotrexate resistant rebounds, as well as a paradoxical flare of pustular psoriasis with TNF- $\alpha$ antagonists, have been reported [6]. Our case showed not only an excellent response of GPP to infliximab,
1
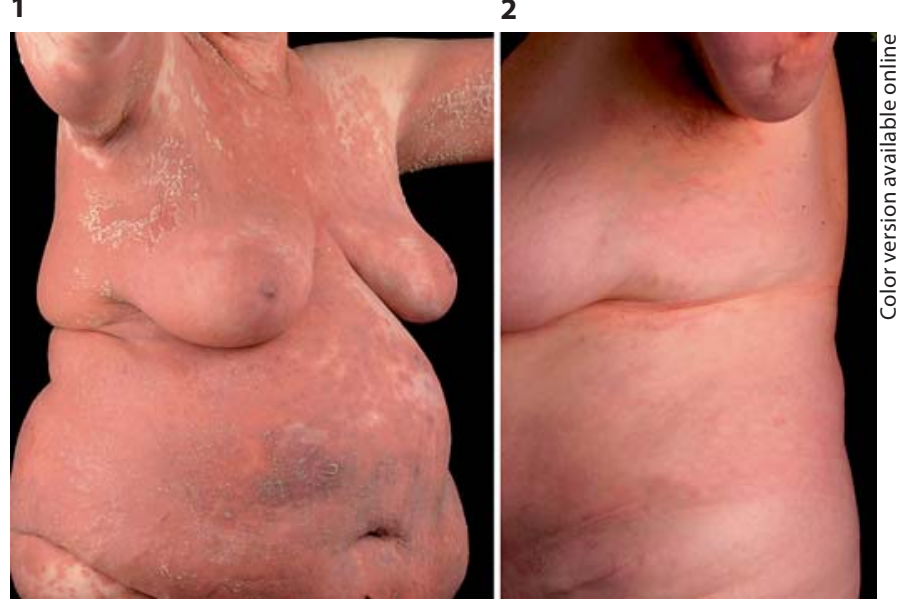

Fig. 1. Erythematous pustular eruption 5 weeks after efalizumab withdrawal.

Fig. 2. Complete response 42 weeks after the first infliximab infusion and 12 weeks after the second efalizumab course.

\section{KARGER}

(ㄷ) 2008 S. Karger AG, Basel

Fax +41 613061234 E-Mail karger@karger.ch www.karger.com 
but, more interestingly, the maintenance of the complete response after the switch to efalizumab ('hit and run approach'). The rotational or sequential therapy with biologicals for psoriasis represents a new and not yet standardised approach; only few reports with different results are present in the literature regarding chronic plaque psoriasis, and, concerning GPP, a sequential therapy using infliximab and etanercept has been reported in only 1 patient by Weisenseel and Prinz [7]. The widest experience with 'hit and run therapy' (infliximab and efalizumab) was reported by Barde et al. [1], including 5 patients with excellent initial responses to infliximab and failure during the long-term maintenance phase (after 6 months) with efalizumab. In contrast to Barde et al. [1] our patient received 'hit and run therapy' with infliximab and efalizumab, with a previous history of complete response to efalizumab; so, the response to efalizumab was confirmed in 2 different circumstances: the first time for the chronic plaque psoriasis unresponsive to ciclosporin, and the second time as maintenance therapy after infliximab. In our patient, the sequential therapy combined the fast onset of action of TNF- $\alpha$-blocking antibodies with the long-term efficacy of the anti-CD11a antibodies, resulting in the rapid achievement of remission (without adverse events) with infliximab and the maintenance of the results (with a safe profile over time) with efalizumab. In our case, the sequential therapy with infliximab and efalizumab should be considered as a 'rescue' treatment for an efalizumab rebound phenomenon that manifested as a generalized pustular eruption in a patient previously responsive to efalizumab for chronic plaque psoriasis; this treatment experience should not be extended to pustular psoriasis in general. Further studies are needed to decide if efalizumab can be considered to be a good choice for rotational and/or sequential therapy.

\section{References}

$\checkmark 1$ Barde C, Thielen AM, Saurat JH: Infliximab then efalizumab, the 'hit and run' approach does not work. Dermatology 2008;216:171-172.

$\checkmark 2$ Thielen AM, Kuenzli S, Saurat JH: Cutaneous adverse events of biological therapy for psoriasis: review of the literature. Dermatology 2005;211:209-217.

-3 Gaylor ML, Duvic M: Generalized pustular psoriasis following withdrawal of efalizumab. J Drugs Dermatol 2004;3:77-79.

-4 Trent JT, Kerdel FA: Successful treatment of Von Zumbusch pustular psoriasis with infliximab. J Cutan Med Surg 2004;8:224-228.

5 Schmick K, Grabbe J: Recalcitrant, generalized pustular psoriasis: rapid and lasting therapeutic response to antitumour necrosis factor-alpha antibody (infliximab). Br J Dermatol 2004;150:367.

6 Thielen AM, Barde C, Saurat JH: Infliximab- and methotrexate-resistant rebound of psoriasis after discontinuation of efalizumab (Rapti$\left.\mathrm{va}^{\circledR}\right)$. Br J Dermatol 2006;155:846-847.

7 Weisenseel P, Prinz JC: Sequential use of infliximab and etanercept in generalized pustular psoriasis. Cutis 2006;78:197-199.

$\checkmark 8$ Nast A, Kopp I, Augustin M, Banditt KB, Boehncke WH, Follmann M: German evidence-based guidelines for the treatment of psoriasis vulgaris. Arch Dermatol Res 2007;299:111-138.

Cesare Massone, MD

Department of Dermatology, Medical University of Graz

Auenbruggerplatz 8, AT-8036 Graz (Austria)

Tel. +43316385 2423, Fax +433163852466

E-Mail cesare.massone@klinikum-graz.at 